\title{
The Online Teaching Practice of Course + Ideological and Political Education under COVID-19 Epidemic
}

\author{
Zhang Enzhan ${ }^{\mathrm{a}}$, Zhang Xia ${ }^{\mathrm{b}}$, Zhang Xijun ${ }^{\mathrm{c}}$, Ma Weijun ${ }^{\mathrm{d}}$, Xie Pengshou ${ }^{\mathrm{e}}$ \\ School of Computer and Communication, Lanzhou University of Technology, Lanzhou 730050, China \\ azhangenzhan@126.com \\ $b^{*}$ zhangxia1116@126.com \\ cblueleaf.6@sohu.com \\ d414600181@qq.com \\ exiepsh_lur@163.com
}

\begin{abstract}
Under the influence of the COVID-19, underline education in universities in China was delayed in spring term of 2020. For realizing the teaching objective "Class suspension, no-stop teaching and learning" of China's ministry of education, this paper introduced the online teaching practice of 'Wireless sensor networks' course plus ideological and political education. Thinking about the course highlights, we combined the technology theory in the course with the application of epidemic prevention and control, developed the teaching method of professional technology to solve the current problems. In the teaching, we blended in the education of patriotism, mental health and responsibility, etc. The implementation of ideological and political education in online class has gained the recognition of students.
\end{abstract}

Keywords: COVID-19, Online Teaching, Ideological and Political Education, WSN

\section{新冠疫情下的专业课程思政线上教学实践}

\section{张恩展 ${ }^{\mathrm{a}}$, 张霞 ${ }^{\mathrm{b}}$, 张胥君 ${ }^{\mathrm{c}}$, 马维俊 ${ }^{\mathrm{d}}$, 谢鹏寿 ${ }^{\mathrm{e}}$}

${ }^{1}$ 兰州理工大学计算机与通信学院, 甘肃, 兰州, 中国

a zhangenzhan@126.com

b*zhangxia1116@126.com

cblueleaf.6@sohu.com

d414600181@qq.com

exiepsh_lur@163.com

\section{摘要}

2020 年春季学期线下教学受到突如其来的新冠肺炎疫情影响延期开学。为实现教育部提出 “停 课不停教, 停课不停学” 的教学目标, 本研究尝试 《无线传感器网络》专业课程思政线上教学实 践。针对 《无线传感器网络》的课程特点, 把课程中的技术理论与疫情防控应用相结合, 开展 专业技术解决当下问题的教学方法, 融入爱国思想教育、心理健康教育, 责任教育等。线上课 思政教学的实施, 获得了学生的认可。

关键词: 新冠肺炎, 在线教育, 课程思政, 无线传感器网络 


\section{1. 前言}

突发的新型冠状病毒带来的肺炎疫情 ${ }^{[1]}$ 把 2020 年春季学期的大中小学的线上教育教学推到了历 史的高峰。在极短的时间内, 线上教学快速地覆盖 到全国的所有高校，在我国高等教育历史上是第一 次 ${ }^{[2]}$ 。在这样的背景下如何开展线上专业课程思政 教育? 如何利用好

新冠疫情的社会热点素材结合专业课的特点实施 专业课思政教育是我们专业课教师面临的亟待解 决的问题。本研究从物联网工程专业的专业基础课 程《无线传感器网络》的专业思政教学实践入手, 在确保课程的教学质量和教学效果的同时, 针对 《无线传感器网络》的课程特点, 把课上技术理论 与疫情防控应用相结合, 开展专业技术针对疫情防 空需求解决当下问题的教学方法。在整个教学过程 中, 用抗疫情、献爱心的感人事迹作为事例, 融入 爱国思想教育、心理健康教育, 责任教育等, 做好 课程思政的教育教学工作。

\section{2. 专业课《无线传感器网络》的课程特点}

《无线传感器网络》是一门介绍无线传感器网 络技术和应用的课程。它涉及到传感器技术、通信 技术、计算机技术、控制技术等 ${ }^{[3][4]}$ 。课程内容主 要讲述无线传感器网络的基本概念、技术、理论和 应用。无线传感器网络应用广泛, 横跨多个领域, 实际应用价值巨大。因此, 在当前新冠疫情背景下, 本门课程的教学把课程的各个技术部分与疫情防 控应用相结合, 开展无线传感器网络技术解决新冠 疫情下的人员体温检测联网、疫情物资定位与追踪、 重点人员身份识别与跟踪等基本教学单元。以综合 应用开发项目 (智能小区疫情防控系统设计) 为考 核手段, 锻炼学生的综合设计能力。该教学模式适 合课程教学方法改革中的任务驱动式教学。

\section{3. 教学方案设计}

\section{1. 线上课堂教学平台搭建}

在疫情大背景下, 中国致力于教育教学平台建 设的公司开始发力, 快速建设了线上教育教学平台 供大家使用。因此, 线上教学平台众多, 有超星平 台、 $\mathrm{MOOC}$ 平台、腾讯 $\mathrm{QQ}$ 平台、云班课平台、钉钉 直播教学平台等。各个教学平台提供线上教学方式 灵活多样, 可以进行在线直播教学, 录播教学视屏 上传教学平台, 或者引用已有课程的音视频资料, 还可以多种方式混合等完成课程教学工作。超星学 习通是一个专业的教育学习平台, 为用户提供一个 便捷的线上课程教学平台。《无线传感器网络》的 在线教学内容建设在超星平台上, 本门课的教学方 式采用混合式教学模式。课程门户见图 1, 课程门 户的主页面上有无线传感器网络的架构图, 图下介 绍了开课信息, 图的左侧介绍了课程内容和课程性 质以及课程教学要求。平台具有丰富便捷的功能模 块, 能够协助老师和同学完成课程任务的教学工作。

\section{2. 教学方案设计}

在实现线上课程思政教学工作时, 针对此次大 规模新型冠状病毒疫情, 我们的教学方案设计分别 从技术层面服务疫情和从人文方面感化教育学生 入手, 充分利用超星学习通平台的各项教学服务模 块和丰富的教学资源, 以提高学生的无线传感器网 络专业知识和培养学生的技术使用和开发能力为 目标，把职业素养教育和道德价值教育融入到课程 教学的整个过程, 设计和实施《无线传感器网络》 专业课程思政教学方案。该方案从教学内容、教学 目标、思政目标、教学过程设计、教学方法五个方 面做了教学计划和安排, 具体规划了教学过程和教 学方法, 详细内容见表 1 。 
本门课程介绍了无线传感器网络的基本概念、关键技术、操作系统、数据管理技 术、中间件技术、无线传感器网络的安全技术以及无线传感器网络的应用与发 展。

无线传感器网络是物联网工程或相关专业的专业必修课程。无线传感器网络是集 传感器技术、微电子技术、现代网络和无线通信技术于一体的综合信息处理平 台, 具有广泛的应用前景, 是信息领域最活跃的研究热点之一。通过本课程的学 习, 要求学生掌握无线传感器网络的体系结构和网络传输技术, 掌握无线传感器 网络的胁协议、路由协议等通信协议, 熟愁无线传感器网络的节点定位、目标跟 踪和时间同步等几大支摧技术, 了解无线传感器网络操作系统等应用技术及安全 技术, 为在基于无线传感器网络的系统开发和应用中, 深入利用关键技术打下坚 买基础。在专业人才培养中具有提高学生相关专业基础理论的认知能力、增强学 生丛事物联网等相关技术研究与应用工作的适应能力和开发创新能力的作用。

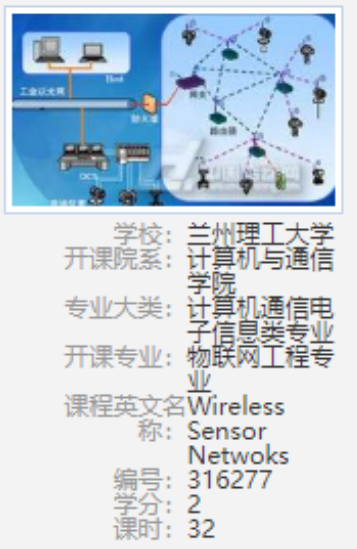

图1. 课程门户

表 1. 教学方案

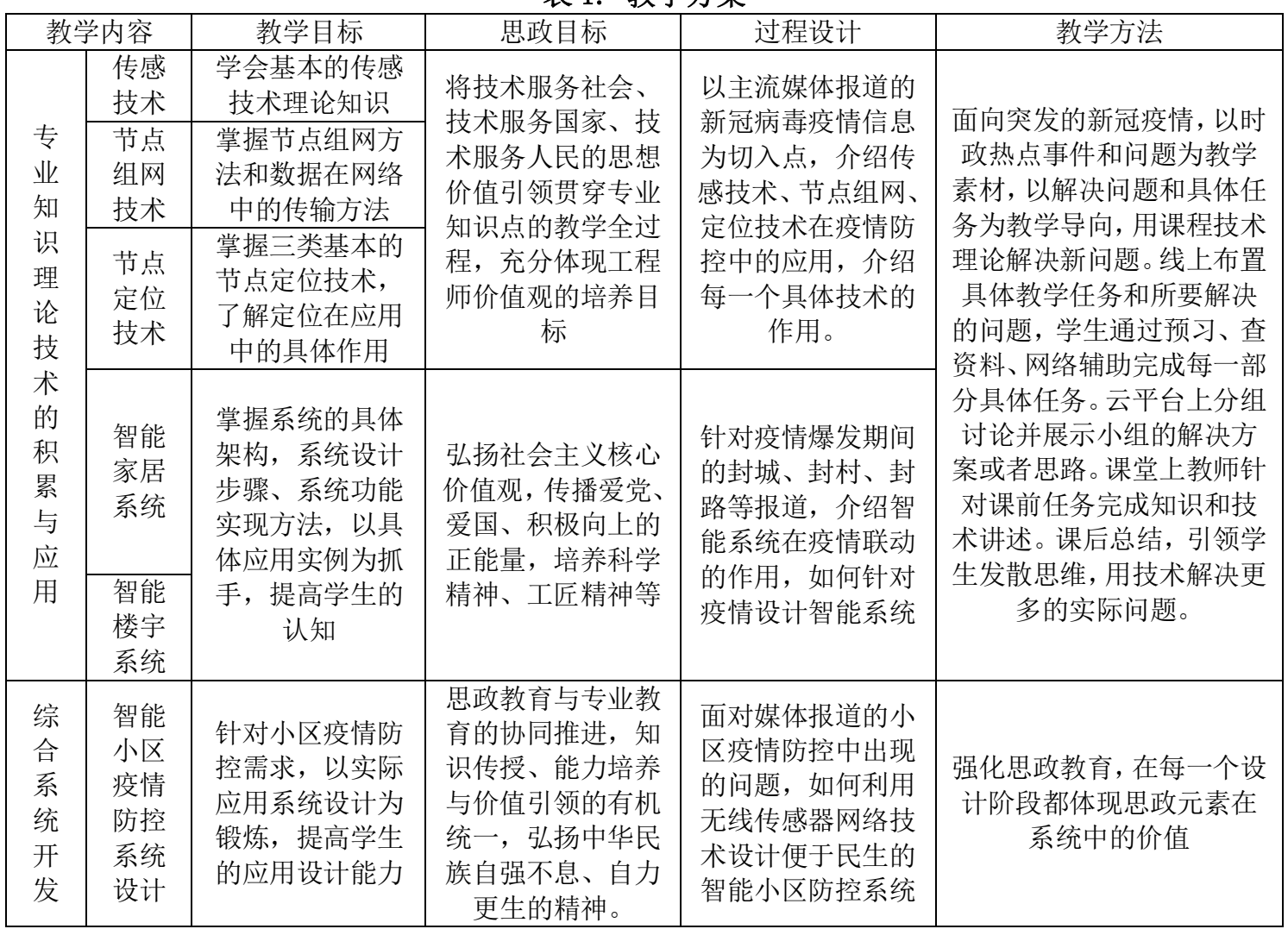

\section{4. 线上教学总结}

信息化教学是信息技术发展的产物, 也是未来 高校教学工作的改革方向。此次疫情虽然给我们国 家高校教学乃至全球高校教学工作的开展带来了
较大影响, 但是从发展信息化教学和探索利用信息 平台进行课程建设方面来讲, 疫情也促使高校进行 了大面积的线上教学尝试, 从而为迈向信息化教学 提供了第一手的经验。经过一段时间的线上教学实 践, 对线上信息化教学有一定的认识, 总结如下: 


\section{1. 信息化教学基础}

计算机技术和互联网技术的发展推动了信息 化教学的改革, 加快了信息技术应用于教学的脚步。 从教学工具到教学方法, 从口头讲述到虚拟仿真, 以及教学方式多样化和教学改革的百花齐放, 无不 是信息技术的基础支撑作用。厦门大学邬大光教授 在文献 [2]中回顾了中国教育技术演进的 40 年，从 传统教育到电化教育, 再到教育信息化, 然后到目 前的第四个阶段智慧教育, 从侧面反映了信息技术 的重大作用。当前存在的问题是不同专业教师的信 息技术能力差异较大，信息化技术的普及成度低和 基础设施欠缺的现状满足不了线上教学的需求。

\section{2. 思政教学与时政相结合}

专业课程思政的教学难点在于将专业课的知 识技能如何与思政教育有机结合在一起 [5]。针对 2020 年突发的新冠疫情, 用时政热点素材武装专业 课思政教学的过程。面对疫情给人们生产生活方式 带来的改变, 应用课程知识技术来解决疫情造成的 问题 (如无线节点测温、无线连接上报数据、安防、 定位等技术协助解决问题, 增加生活生产的便利性 和安全性), 增强学生的使命感和责任感。在线播 报动人事迹, 利用疫情中鲜明动人的事例来鼓舞学 生和感化学生, 进行心理健康教育 [6]。充分利用 时政热点素材武装专业思政教学, 丰富教学过程和 体现教书育人的宗旨。

\section{3. 线上教学改革的困难之处}

每次教育教学的改革都包含着两个方面, 一个 是教育教学理念的变革, 一个是教育教学实践的验 证。对于传统教育方式的执行者和管理者来说，在 教学观念问题上无法快速转变适应线上教学的方 式。究其原因有二, 一是思想和行动的惰性导致不 愿主动改变固有的教学模式和转变教学角色, 更不 适应新技术对教学模式的冲击; 二是在还未看到线 上教学的效果之前对线上教学的质疑。尽管这次疫 情给高校教师一个线上教学实践的机会, 但没有思 想上的认可和角色转变, 也很难把线上教学的价值 发挥出来。

\section{4. 教学效果评价}

教学效果是衡量教学活动结果的重要指标。传 统教学效果的衡量方式是线下考试或者考核, 这种 评价方式单一且武断, 注重的是结果。线上教学效 果评价从多个维度进行, 课前的线上调查、课程进 行中的弹框问题互动、课后的回馈、学任务的进度 跟踪、线上考试等。尽管多维度的评价给学生带来
较大的学习压力, 有被绑架和监督的感觉, 且师生 之间产生了不信任感和距离感。但是这种多维度的 评价能够督促学生按时做好课程的预习、加强了课 程中的互动和及时地评价了学习效果, 让学生有种

“所见即所得” 的感觉, 增强了学习的获得感。

\section{5. 结语}

新型冠状病毒疫情给高校教学改革带来了线 上教学的实践机会也带来了反思。尽管传统课堂还 占据着主流教学模式, 但从更长远的教学发展来看, 线上教育将是未来终身教育的主要支撑。随着移动 多媒体的发展, 线上教育提供了随时随地的学习环 境, 借助信息技术大力引导、发展、管理线上教育 更有利于人才培养。同时, 利用线上教学开展课程 思政教育, 更便于引征网络资源和社会热点素材, 结合鲜活事例进行思政教育、爱国教育、心理健康 教育等, 提高了教学的生动性和教学效果, 增强了 专业课在教学过程中的思想政治教育作用。

\section{项目基金}

本文为教育部新工科研究与实践项目 “欠发达地区高校新工科物联网工程专业 建设”和 2019 年兰州理工大学高教研究项 目 (编号 GJ2019C-28) 的阶段性成果之一。

\section{REFERENCES}

[1] Jin, L. Zhao, Y. Zhou, J. Tao, M. Yang, Y. Wang, X. Ye, P. Shan, S. Yuan, H. (2020) Distributions of time, place, and population of novel coronavirus disease 2019 (COVID-19) from January 20 to February 10, 2020, in China. Revista Clínica Española (English Edition), 1-6.

[2] Wu, D.G. (2020) The Retrospect and Reflection of Educational Technology Evolution: Online Teaching in Universities under the Epidemic Situation. China higher education, 04: 1-6+11.

[3] Akyildiz, I.F. Vuran M.C. (2010) Wireless sensor networks. WILEY Press, New Jersey.

[4] Forster A. (2016) Introduction to wireless sensor networks. WILEY Press, New Jersey.

[5] Rui, H.J. Sun, T.T. Liu, Y. Wu, H. (2020) Practical Research on the Classroom in the Air in the course ideological and political teaching. Chinese Journal of Multimedia and Network Teaching, 03:174-175. 
[6] Zhu, X.L. Liu, D. Yan, F. Qu, W. Fan, H.Z. Zhao, Y. Wang, Z.R. Tan, Y.L. Ren, Y.P. Tan, S.P. (2020) Psychological status of school students and employees during the COVID-19 epidemic. Chinese Mental Health Journal, 06: 549-554. 